\title{
Papers
}

\section{Passive smoking and risk of coronary heart disease and stroke: prospective study with cotinine measurement}

Peter H Whincup, Julie A Gilg, Jonathan R Emberson, Martin J Jarvis, Colin Feyerabend, Andrew Bryant, Mary Walker, Derek G Cook

\begin{abstract}
Objective To examine the associations between a biomarker of overall passive exposure to tobacco smoke (serum cotinine concentration) and risk of coronary heart disease and stroke. Design Prospective population based study in general practice (the British regional heart study).

Participants 4729 men in 18 towns who provided baseline blood samples (for cotinine assay) and a detailed smoking history in 1978-80.

Main outcome measure Major coronary heart disease and stroke events (fatal and non-fatal) during 20 years of follow up. Results 2105 men who said they did not smoke and who had cotinine concentrations $<14.1 \mathrm{ng} / \mathrm{ml}$ were divided into four equal sized groups on the basis of cotinine concentrations. Relative hazards ( $95 \%$ confidence intervals) for coronary heart disease in the second (0.8-1.4 ng/ml), third (1.5-2.7 ng/ml), and fourth $(2.8-14.0 \mathrm{ng} / \mathrm{ml})$ quarters of cotinine concentration compared with the first $(\leq 0.7 \mathrm{ng} / \mathrm{ml})$ were 1.45 (1.01 to 2.08 ), 1.49 (1.03 to 2.14 ), and 1.57 (1.08 to 2.28), respectively, after adjustment for established risk factors for coronary heart disease. Hazard ratios (for cotinine $0.8-14.0 v \leq 0.7 \mathrm{ng} / \mathrm{ml}$ ) were particularly increased during the first $(3.73,1.32$ to 10.58$)$ and second five year follow up periods $(1.95,1.09$ to 3.48$)$ compared with later periods. There was no consistent association between cotinine concentration and risk of stroke.

Conclusion Studies based on reports of smoking in a partner alone seem to underestimate the risks of exposure to passive smoking. Further prospective studies relating biomarkers of passive smoking to risk of coronary heart disease are needed.
\end{abstract}

\section{Introduction}

Active cigarette smoking is a well established major preventable risk factor for coronary heart disease (CHD). ${ }^{1}$ Many studies have reported that passive smoking is also associated with increased risk of CHD. ${ }^{23}$ Generally such studies have compared the risks of non-smokers who do or do not live with cigarette smokers, ${ }^{4-9}$ though a few have also considered occupational exposure. ${ }^{10-12}$ Meta-analyses of case-control and cohort studies examining the effect of living with a cigarette smoker on risk among non-smokers have generally shown an overall increase in risk of about one quarter, after adjustment for potential confounding factors $^{23}$ and with little evidence of publication bias. Passive smoking may also be related to risk of stroke. ${ }^{13}$

Although living with someone who smokes is an important component of exposure to passive smoking, it accounts for less than half of the variation in cotinine concentration among non- smokers ${ }^{14}$ and does not take account of additional exposure in workplaces and in public places (particularly pubs and restaurants). ${ }^{15}$ Biomarkers of passive exposure to smoking, particularly cotinine (a nicotine metabolite), can provide a summary measure of exposure from all these sources. ${ }^{16}$ Although cotinine concentration in non-smokers has been related to prevalent $\mathrm{CHD},{ }^{17}$ there are no published reports of the prospective associations between serum cotinine concentration and risk of CHD and stroke in non-smokers. We have examined these associations in the British regional heart study, a prospective study of cardiovascular disease in middle aged men, using retained baseline samples for retrospective measurement of cotinine.

\section{Methods}

The British regional heart study is a prospective study of cardiovascular disease in 7735 men aged 40-59 years selected from the age and sex registers of one general practice in each of 24 towns in England, Wales, and Scotland (78\% response rate). ${ }^{18}$

\section{Baseline assessment}

In 1978-80, research nurses administered a questionnaire on present and previous smoking habits (cigarettes, cigar, pipe), alcohol intake, physical activity, and medical history (including angina, myocardial infarction, stroke, and diabetes diagnosed by a doctor). Participants also completed a questionnaire on chest pain (Rose, World Health Organization). Two seated blood pressure measurements were taken with a London School of Hygiene and Tropical Medicine sphygmomanometer; the mean was adjusted for observer variation within each town. Non-fasting total serum cholesterol concentration was measured with a modified Liebermann-Burchard method on a Technicon SMA 12/60 analyser. High density lipoprotein (HDL) cholesterol was measured by the same procedure after precipitation with magnesium phosphotungstate. Serum samples were placed in long term storage at $-20^{\circ} \mathrm{C}$ in the last 18 study towns. In 2001-2, these were thawed and cotinine concentration was measured with a gas-liquid chromatography method (detection limit $0.1 \mathrm{ng} / \mathrm{ml}){ }^{19}$

\section{Follow up}

All men were followed up for all cause mortality and cardiovascular morbidity. We collected information on deaths through the established "flagging" procedures provided by the NHS central registers. We obtained information on non-fatal CHD events and strokes from general practitioners' reports, supplemented by reviewing patients' records every two years throughout follow up. 
Major CHD events included deaths with coronary heart disease as the underlying cause, including sudden death of presumed cardiac origin (international classification of diseases, ninth revision (ICD-9), codes 410-414) and non-fatal myocardial infarction, diagnosed in accordance with standard WHO criteria. ${ }^{18}$ Stroke events included deaths with cerebrovascular disease as the underlying cause (ICD-9 codes 430-438) and non-fatal stroke diagnosed in accordance with WHO criteria. ${ }^{18}$ The analyses presented are based on all first major CHD or stroke events during the follow up period to December 2000, with an average follow up of 18.5 years for men who had no myocardial infarction or stroke (range $0.2-20.0$ years).

\section{Definition of baseline smoking status}

Men were classified as "current non-smokers" at baseline if they reported that they did not smoke cigarettes, cigars, or a pipe and had a serum cotinine concentration $<14.1 \mathrm{ng} / \mathrm{ml}^{20}{ }^{20}$ Among these men, "lifelong non-smokers" were those who reported never having smoked cigarettes, cigars, or a pipe. For comparison purposes, "light active smokers" were men who reported smoking 1-9 cigarettes a day, irrespective of cotinine concentration.

\section{Other definitions}

Pre-existing CHD included one or more of angina or possible myocardial infarction, or both, on the WHO Rose questionnaire; electrocardiographic evidence of definite or possible myocardial infarction or ischaemia; or participant's recall of myocardial infarction or angina diagnosed by a doctor. Study towns were considered to be in the south if they were to the south or east of a line joining the River Severn and the Wash. Physical activity and alcohol intake were categorised as in earlier reports. ${ }^{21}{ }^{22}$

\section{Statistical methods}

We used Cox proportional hazards models, stratified by town of residence, to examine the independent contribution of serum cotinine concentration to the risks of CHD and stroke. These produced relative hazards, adjusted for age and other risk factors, for each quarter of the distribution of serum cotinine concentration compared with the lowest. We carried out overall tests of the association, fitting the continuous relation between $\log$ cotinine concentration and risk of CHD. Relative hazard estimates for each five year interval were calculated by fitting interaction terms with time (using three binary factors to separate the effects in the second, third, and fourth intervals from those in the first). Kaplan-Meier curves were used to display the differences in incidence of major CHD by cotinine exposure group; differences were assessed using the log rank test. All $P$ values were two sided.

We fitted age, body mass index, height, systolic blood pressure, diastolic blood pressure, serum total cholesterol, high density lipoprotein cholesterol, white cell count, lung function (forced expiratory volume in one second $\left(\mathrm{FEV}_{1}\right)$ ), and triglycerides as continuous variables. Physical activity was fitted as a factor with four levels (none, occasional, light, moderate or more), alcohol intake with three levels (none/occasional, light/moderate, heavy), and social class with seven levels (six registrar general categories and Armed Forces). History of cigarette smoking, pre-existing $\mathrm{CHD}$, and diabetes were fitted as dichotomous variables.

\section{Results}

In the last 18 towns of the study, 5661 men took part (78\% response rate). For 4729 of these we had detailed histories on smoking and blood samples for cotinine analysis. These men

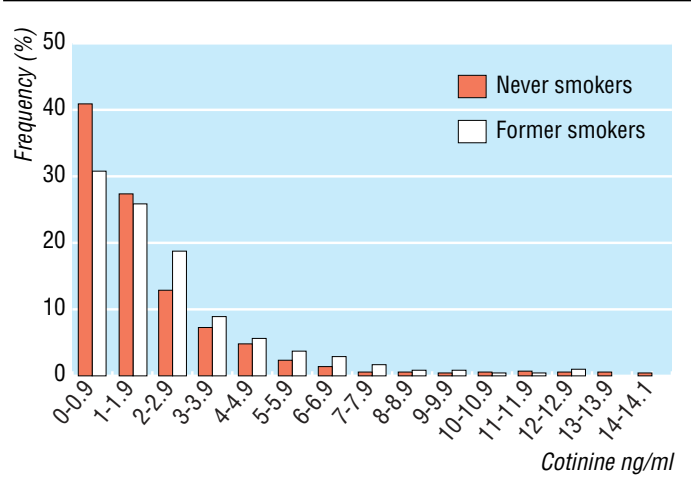

Fig 1 Distribution of serum cotinine concentrations among current non-smokers; lifelong non-smokers and former smokers are shown separately

resembled the whole study population in reported smoking habits and risks of CHD and stroke. A total of 2158 men reported that they were current non-smokers, of whom $2105(97.5 \%)$ had serum cotinine concentrations $<14.1 \mathrm{ng} / \mathrm{ml}$. Of these, 945 men were classified as lifelong non-smokers, the remaining 1160 as former smokers. The cotinine distributions of these two groups (fig 1) were skewed, with a slightly higher geometric mean cotinine among former smokers than among lifelong nonsmokers (1.49 v $1.18 \mathrm{ng} / \mathrm{ml})$. Few men in either group had cotinine concentrations close to the $14.1 \mathrm{ng} / \mathrm{ml}$ cut off.

Serum cotinine and cardiovascular risk factors-Among current non-smokers, cotinine concentrations were not consistently related to age, total cholesterol concentration, physical activity score, or prevalent CHD but showed graded positive associations with mean body mass index, systolic and diastolic blood pressure, high density lipoprotein cholesterol, white cell count, and triglycerides (weakly) and positive associations with the prevalence of former smoking, heavy drinking, and manual occupation (table 1). Cotinine concentrations were inversely associated with $\mathrm{FEV}_{1}$, prevalence of low alcohol intake, and residence in southern England. These associations were generally little affected when we excluded former smokers. Light active smokers had lower mean body mass index, diastolic blood pressure, and $\mathrm{FEV}_{1}$ and a higher mean white cell count than men who did not smoke.

Serum cotinine concentration and CHD risk-We examined the association between quarters of the cotinine distribution and CHD hazard ratios among all 2105 current non-smokers using the complete follow up period (table 2). The risks in the upper three cotinine groups were markedly higher than the risk in the lowest group, with a relative hazard of 1.61 in the highest group in the simplest model (adjusted for town and age), a hazard estimate similar to that of light active smokers. The association between cotinine concentration and CHD seemed graded and was not markedly affected by adjustment for other cardiovascular risk factors. The results of analyses restricted to lifelong nonsmokers were similar, though the confidence intervals were wider. Exclusion of men with pre-existing CHD had no effect on these findings (data not presented). When we examined the overall association between cotinine concentration and CHD, we found that a doubling of cotinine concentration was associated with a hazard increase of $16 \%(95 \%$ confidence interval $6 \%$ to $27 \%)$.

Influence of follow up period -In a Kaplan-Meier plot showing the cumulative proportions of men with major CHD over time among three groups (light passive (lowest cotinine quarter), heavy passive (upper three cotinine quarters), and light active 
Table 1 Means (SDs) and numbers (percentages) of cardiovascular risk factors by cotinine concentration: non-smokers and light active cigarette smokers

\begin{tabular}{|c|c|c|c|c|c|c|}
\hline & \multicolumn{4}{|c|}{ Passive smoke exposure (ng/ml cotinine) } & \multirow{2}{*}{$\begin{array}{c}\text { Active smokers } \\
\text { (1-9/day) }\end{array}$} & \multirow[b]{2}{*}{$P$ value for trend ${ }^{*}$} \\
\hline & $\leq 0.7$ & $0.8-1.4$ & $1.5-2.7$ & $2.8-14.0$ & & \\
\hline Mean cotinine (ng/ml) & 0.5 & 1.1 & 2.0 & 4.9 & 138.4 & - \\
\hline No of men & 575 & 508 & 506 & 516 & 192 & - \\
\hline Age (years) & $50.5(5.7)$ & $49.9(5.7)$ & $50.2(5.8)$ & $50.5(6.1)$ & $50.7(5.7)$ & 0.96 \\
\hline $\mathrm{BMI}\left(\mathrm{kg} / \mathrm{m}^{2}\right)$ & $25.5(2.9)$ & $25.4(3.1)$ & $26.3(3.1)$ & $26.5(3.4)$ & $25.0(3.4)$ & $<0.001$ \\
\hline Height (cm) & $174.0(6.6)$ & $173.5(6.6)$ & $173.5(6.6)$ & $172.4(6.5)$ & $172.8(6.1)$ & 0.03 \\
\hline Systolic blood pressure $(\mathrm{mm} \mathrm{Hg})$ & $144(22)$ & $145(21)$ & $147(20)$ & $151(22)$ & $144(22)$ & $<0.001$ \\
\hline Diastolic blood pressure $(\mathrm{mm} \mathrm{Hg})$ & $82(14)$ & $83(13)$ & $85(14)$ & $87(15)$ & $83(14)$ & $<0.001$ \\
\hline Total cholesterol $(\mathrm{mmol} / \mathrm{l})$ & $6.3(1.0)$ & $6.3(1.0)$ & $6.3(1.0)$ & $6.3(1.0)$ & $6.3(1.0)$ & 0.50 \\
\hline HDL cholesterol $(\mathrm{mmol} / \mathrm{l})$ & $1.14(0.25)$ & $1.16(0.27)$ & $1.14(0.26)$ & $1.20(0.26)$ & $1.15(0.25)$ & $<0.001$ \\
\hline White cell count $\left(10^{9} / l\right)$ & $6.4(1.4)$ & $6.5(1.4)$ & $6.6(2.3)$ & $6.7(1.4)$ & $7.2(1.6)$ & 0.02 \\
\hline $\mathrm{FEV}_{1}(\mathrm{ml})$ & 357 (68) & $355(72)$ & $346(74)$ & $329(80)$ & $329(78)$ & $<0.001$ \\
\hline Triglycerides† $(\mathrm{mmol} / \mathrm{l})$ & 1.65 & 1.61 & 1.77 & 1.78 & 1.74 & 0.04 \\
\hline Evidence of $\mathrm{CHD}$ & $134(23)$ & $126(25)$ & $117(23)$ & $142(28)$ & $48(25)$ & 0.19 \\
\hline Diabetes (diagnosed by doctor) & $8(1)$ & $8(2)$ & $7(1)$ & $5(1)$ & $4(2)$ & - \\
\hline Physical activity: none or occasional & $182(32)$ & $169(33)$ & $163(32)$ & $208(40)$ & $70(36)$ & 0.25 \\
\hline Alcohol intake: never or occasional & $261(45)$ & $189(37)$ & $145(29)$ & $104(20)$ & $52(27)$ & $<0.001$ \\
\hline Alcohol intake: heavy (>6 drinks/day) & $10(2)$ & $22(4)$ & $38(8)$ & $85(16)$ & $22(11)$ & $<0.001$ \\
\hline Former smoker & $267(46)$ & $259(51)$ & $309(61)$ & $325(63)$ & - & $<0.001$ \\
\hline Manual workers & $246(43)$ & $258(51)$ & $287(57)$ & $346(67)$ & $120(63)$ & $<0.001$ \\
\hline Live in south & $303(53)$ & $196(39)$ & $158(31)$ & $113(22)$ & $64(33)$ & $<0.001 \ddagger$ \\
\hline
\end{tabular}

${ }^{*}$ Across passive smoking groups only. Adjusted for age and town.

†Geometric means as log transformed.

†Adjusted for age only.

(1-9 cigarettes/day)) we found that the heavy passive and light active groups diverged rapidly from the light passive group during the first years of follow up but remained almost parallel during later years (fig 2). The corresponding hazard ratios for cotinine and risk of $\mathrm{CHD}$ in separate five year follow up periods were highest in the early years of follow up and declined with increasing duration of follow up (table 3). These patterns were little affected by adjustment for cardiovascular risk factors, and again the hazard ratios for the heavier passive smoking groups were comparable with those of light active smokers. Restriction of these analyses to lifelong non-smokers or to men with no evidence of pre-existing CHD had no material effect on the results.

Serum cotinine exposure and stroke-There was no strong association between cotinine concentration and stroke among non-smokers, either before or after adjustment for major cardiovascular risk factors (table 4). Analyses based on lifelong non-smokers showed similar results. For stroke, there was no strong evidence that hazard ratios changed over time (data not presented).

Table 2 Hazard ratios for cotinine group and risk of coronary heart disease (CHD) over 20 years of follow up

Cotinine concentration $(\mathrm{ng} / \mathrm{ml})$

\begin{tabular}{|c|c|c|c|c|c|c|}
\hline & \multicolumn{4}{|c|}{ Cotinine concentration (ng/ml) } & \multirow[b]{2}{*}{ Active smokers (1-9/day) } & \multirow[b]{2}{*}{$P$ value for trend ${ }^{*}$} \\
\hline & $\leq 0.7$ & $0.8-1.4$ & $1.5-2.7$ & $2.8-14.0$ & & \\
\hline \multicolumn{7}{|l|}{ All men } \\
\hline Mean (SD) cotinine (ng/ml) & $0.4(0.2)$ & $1.1(0.2)$ & $2.0(0.4)$ & $4.9(2.1)$ & $138.4(149.3)$ & \\
\hline No of participants & 575 & 508 & 506 & 516 & 192 & \\
\hline No of events & 61 & 74 & 81 & 92 & 34 & \\
\hline Person years & 10488 & 8966 & 8897 & 8823 & 3317 & \\
\hline CHD rate/1000 person years & 5.82 & 8.25 & 9.10 & 10.43 & 10.25 & \\
\hline \multicolumn{7}{|l|}{ Hazard ratio $(95 \% \mathrm{Cl}) \dagger$ : } \\
\hline Adjustment 1 & 1.00 & 1.50 (1.06 to 2.12$)$ & 1.56 (1.11 to 2.20$)$ & 1.61 (1.15 to 2.27$)$ & 1.65 (1.08 to 2.54$)$ & 0.001 \\
\hline Adjustment 2 & 1.00 & 1.47 (1.04 to 2.07 ) & 1.43 (1.00 to 2.02) & 1.46 (1.02 to 2.07$)$ & 1.60 (1.03 to 2.48$)$ & 0.008 \\
\hline Adjustment 3 & 1.00 & 1.45 (1.01 to 2.08) & 1.49 (1.03 to 2.14) & 1.57 (1.08 to 2.28$)$ & 1.66 (1.04 to 2.68$)$ & 0.001 \\
\hline \multicolumn{7}{|l|}{ Excluding former smokers } \\
\hline Mean (SD) cotinine (ng/ml) & $0.4(0.2)$ & $1.1(0.2)$ & $2.0(0.4)$ & $5.0(2.4)$ & $138.4(149.3)$ & \\
\hline No of participants & 308 & 249 & 197 & 191 & 192 & \\
\hline No of events & 31 & 27 & 25 & 28 & 34 & \\
\hline Person years & 5752 & 4530 & 3519 & 3388 & 3317 & \\
\hline CHD rate/1000 person years & 5.39 & 5.96 & 7.10 & 8.27 & 10.25 & \\
\hline \multicolumn{7}{|l|}{ Hazard ratio $(95 \% \mathrm{Cl}) \dagger$ : } \\
\hline Adjustment 1 & 1.00 & 1.32 (0.78 to 2.25$)$ & 1.44 (0.83 to 2.50$)$ & 1.55 (0.90 to 2.69) & 1.77 (1.07 to 2.96$)$ & 0.006 \\
\hline Adjustment 2 & 1.00 & 1.40 (0.82 to 2.39$)$ & 1.63 (0.93 to 2.86) & 1.46 (0.83 to 2.56$)$ & 1.78 (1.07 to 2.99 ) & 0.007 \\
\hline Adjustment 3 & 1.00 & 1.54 (0.88 to 2.69$)$ & 1.89 (1.05 to 3.39$)$ & 1.67 (0.91 to 3.07$)$ & 2.05 (1.14 to 3.69 ) & 0.001 \\
\hline
\end{tabular}

*From tests for linear trend between log (cotinine) concentration and CHD hazard across passive smoking groups.

tFor CHD: adjustment 1 stratified by town and adjusted for age; adjustment 2 additionally adjusted for systolic blood pressure, diastolic blood pressure, total cholesterol, HDL cholesterol, FEV height, and pre-existing CHD; adjustment 3 additionally adjusted for BMI, triglycerides, white cell count, diabetes, physical activity (none, occasional, light, moderate or more), alcohol intake (none/occasional, light/moderate, heavy), and social class (I, II, III non-manual, III manual, IV, V, and Armed Forces). 


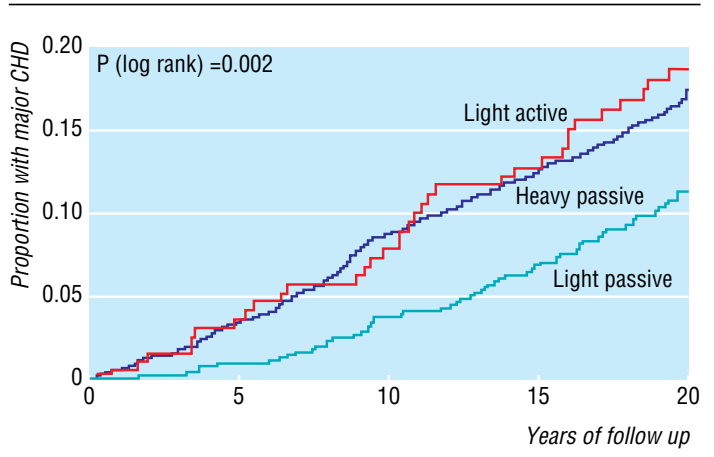

Fig 2 Proportion of men with major CHD by years of follow up in each smoking group. "Light passive" refers to lowest quarter of cotinine concentration among non-smokers $(0-0.7 \mathrm{ng} / \mathrm{ml})$, "heavy passive" to upper three quarters of cotinine concentration combined (0.8 to $14.0 \mathrm{ng} / \mathrm{ml}$ ), "light active" to men smoking 1-9 cigarettes a day

\section{Discussion}

We believe this is the first published report to relate passive exposure to smoking, based on cotinine measurements, prospectively to the risks of $\mathrm{CHD}$ and stroke, although cotinine concentration has been related to prevalence of $\mathrm{CHD} .{ }^{17}$ Our study was conducted in a geographically and socially representative sample of middle aged men. ${ }^{18}$ Cotinine is a highly sensitive and highly specific marker of active and passive exposure to tobacco $^{23}$; its stability in serum over long periods has been demonstrated. ${ }^{24}$ We were able to adjust for a wide range of potential confounding variables, and this had little effect on the results. This agrees with the earlier reports of Law and He, which suggested that the contribution of confounding factors to the association between passive smoking and CHD was modest. ${ }^{23} \mathrm{~A}$ greater concern is the possibility that men in the higher cotinine groups were smoking cigarettes on an intermittent basis. Although it is difficult to exclude this possibility completely, study participants had no specific incentive to provide inaccurate information, there was close agreement between reported smoking and cotinine concentration, and the cotinine threshold was conservative and rarely approached, even among former smokers. In addition, almost all surviving current non-smokers (99\%) continued to report that they were non-smokers in responses to postal questionnaires five and 12 years later.

Table 3 Cotinine group and risk of coronary heart disease (CHD): hazard ratios (95\% confidence intervals) for specific 5 year follow up periods

\begin{tabular}{|c|c|c|c|c|c|}
\hline & \multicolumn{5}{|c|}{ Follow up period (years) } \\
\hline & $0-4$ & $5-9$ & $10-14$ & & $15-20$ \\
\hline \multicolumn{6}{|c|}{ Passive smokers* $\dagger$} \\
\hline Adjustment 1 & 3.45 (1.36 to 8.80$)$ & 1.90 (1.09 to 3.31$)$ & 1.27 (0.72 to 2.22 ) & 1.09 & (0.66 to 1.82 ) \\
\hline Adjustment 2 & 3.14 (1.23 to 8.04$)$ & 1.93 (1.09 to 3.42 ) & 1.10 (0.63 to 1.95$)$ & 1.00 & (0.60 to 1.67$)$ \\
\hline Adjustment 3 & $3.73(1.32$ to 10.58$)$ & 1.95 (1.09 to 3.48 ) & 1.13 (0.63 to 2.04$)$ & 1.04 & (0.62to1.76) \\
\hline \multicolumn{6}{|c|}{ Low active smokersł‡ } \\
\hline Adjustment 1 & 3.44 (1.07 to 11.02$)$ & 1.50 (0.63 to 3.55$)$ & 1.59 (0.70 to 3.62$)$ & 1.41 & (0.66 to 3.03 ) \\
\hline Adjustment 2 & 2.99 (0.90 to 9.97) & 1.58 (0.66 to 3.80$)$ & 1.43 (0.61 to 3.38$)$ & 1.47 & (0.68 to 3.15$)$ \\
\hline Adjustment 3 & 3.32 (0.87 to 12.64$)$ & 1.66 (0.66 to 4.18$)$ & 1.71 (0.71 to 4.10$)$ & 1.34 & (1.23 to 1.47$)$ \\
\hline
\end{tabular}

*Hazard ratios for CHD events for passive smokers with cotinine above $0.7 \mathrm{v}$ passive smokers with cotinine below 0.7 .

FFor CHD: adjustment 1 stratified by town and adjusted for age; adjustment 2 additionally adjusted for systolic blood pressure, diastolic blood pressure, total cholesterol, HDL cholesterol, FEV ${ }_{1}$, height, and pre-existing CHD; adjustment 3 additionally adjusted for BMI, triglycerides, white cell count, diabetes, physical activity (none, occasional, light, moderate or more), alcohol intake (none/occasional, light/moderate, heavy), and social class (I, II, III non-manual, III manual, IV, V, and Armed Forces).

$\ddagger$ Hazard ratios for CHD events for low active smokers (1-9 cigarettes/day) $v$ passive smokers with cotinine below 0.7 .

Table 4 Hazard ratios for cotinine group and risk of stroke over 20 years of follow up

\begin{tabular}{|c|c|c|c|c|c|c|}
\hline & \multicolumn{4}{|c|}{ Cotinine concentration (ng/ml) } & \multirow[b]{2}{*}{ Active smokers (1-9/day) } & \multirow[b]{2}{*}{ Test for trend } \\
\hline & $\leq 0.7$ & $0.8-1.4$ & $1.5-2.7$ & $2.8-14.0$ & & \\
\hline \multicolumn{7}{|l|}{ All men } \\
\hline Mean (SD) cotinine (ng/ml) & $0.4(0.2)$ & $1.1(0.2)$ & $2.0(0.4)$ & $4.9(2.1)$ & $138.4(149.3)$ & \\
\hline No of men & 575 & 508 & 506 & 516 & 192 & \\
\hline No of events & 35 & 22 & 27 & 28 & 17 & \\
\hline Person years & 10552 & 9162 & 9159 & 9112 & 3316 & \\
\hline $\begin{array}{l}\text { Stroke rate/1000 person } \\
\text { years) }\end{array}$ & 3.32 & 2.40 & 2.95 & 3.07 & 5.13 & \\
\hline \multicolumn{7}{|l|}{ Hazard ratios $(95 \% \mathrm{Cl}) \dagger$ : } \\
\hline Adjustment 1 & 1.00 & 0.76 (0.44 to 1.31$)$ & $0.83(0.50$ to 1.40$)$ & $0.87(0.52$ to 1.47$)$ & 1.48 (0.81 to 2.69$)$ & 0.73 \\
\hline Adjustment 2 & 1.00 & 0.81 (0.47 to 1.41$)$ & 0.87 (0.51 to 1.47) & 0.78 (0.45 to 1.35$)$ & 1.39 (0.74 to 2.60$)$ & 0.91 \\
\hline Adjustment 3 & 1.00 & $0.83(0.46$ to 1.47$)$ & 0.94 (0.54 to 1.64) & $0.77(0.42$ to 1.41$)$ & $1.45(0.71$ to 2.96$)$ & 0.99 \\
\hline \multicolumn{7}{|l|}{ Excluding former smokers } \\
\hline Mean (SD) cotinine (ng/ml) & $0.4(0.2)$ & $1.1(0.2)$ & $2.0(0.4)$ & $5.0(2.4)$ & $138.4(149.3)$ & \\
\hline No of men & 308 & 249 & 197 & 191 & 192 & \\
\hline No of events & 14 & 10 & 6 & 11 & 17 & \\
\hline Person years & 5804 & 4610 & 3625 & 3458 & 3316 & \\
\hline Stroke rate/person years) & 2.41 & 2.17 & 1.66 & 3.18 & 5.13 & \\
\hline \multicolumn{7}{|l|}{ Hazard ratios $(95 \% \mathrm{Cl}) \dagger$ : } \\
\hline Adjustment 1 & 1.00 & 1.01 (0.43 to 2.35) & 0.66 (0.25 to 1.78) & 1.25 (0.54 to 2.89) & $1.95(0.90$ to 4.22$)$ & 0.52 \\
\hline Adjustment 2 & 1.00 & $1.14(0.48$ to 2.71$)$ & 1.08 (0.38 to 3.02$)$ & 1.34 (0.54 to 3.31$)$ & 2.04 (0.91 to 4.57$)$ & 0.23 \\
\hline Adjustment 3 & 1.00 & 1.34 (0.53 to 3.40$)$ & 1.39 (0.48 to 4.04$)$ & 2.16 (0.80 to 5.80$)$ & 2.69 (1.07 to 6.75$)$ & 0.11 \\
\hline
\end{tabular}

${ }^{*} \mathrm{P}$ values from tests for linear trend between log (cotinine) and stroke hazard across passive smoking groups.

tFor stroke hazard ratios: adjustment 1 stratified by town and adjusted for age; adjustment 2 additionally adjusted for systolic blood pressure, diastolic blood pressure, total cholesterol, HDL cholesterol, FEV ${ }_{1}$, height, and pre-existing CHD; adjustment 3 additionally adjusted for BMI, triglycerides, white cell count, diabetes, physical activity (none, occasional, light, moderate or more), alcohol intake (none/occasional, light/moderate, heavy), and social class (I, II, III non-manual, III manual, IV, V, and Armed Forces). 


\section{Passive smoking and CHD}

Although the study was modest in size with limited precision, our results suggest that the relative risk of $\mathrm{CHD}$ associated with high levels of passive exposure to smoke is greater than that estimated for partner smoking alone, even at exposure levels of 20 cigarettes a day or more. ${ }^{3}$ The similarity of relative risks among participants with substantial exposure to passive smoking and light active exposure to smoking is consistent with earlier findings. ${ }^{2}$ The high relative risk associated with exposure to passive smoking in our study probably reflects the wide range of cotinine concentrations observed among non-smokers; the average concentrations of the highest and lowest cotinine quarters differed almost 10 -fold. This range seems considerably wider than that which might be expected from partner smoking alone. Although no published information on the association of partner smoking to cotinine concentration is available from our study (or from other British studies conducted in the early 1980s), more recent data from the health survey for England suggest that partner smoking is associated with average increases in cotinine concentration of about 3.6-fold. ${ }^{14} \mathrm{~A}$ difference in cotinine concentration of this size would, on the basis of the log cotinine-CHD association defined in the present study, be associated with a relative risk of CHD of about 1.32 (95\% confidence interval 1.12 to 1.55 ) - a figure similar to the estimates obtained in the earlier systematic reviews. ${ }^{2}{ }^{3}$

The marked attenuation in the relative risks relating cotinine and CHD with increasing duration of follow up draws attention to a further possible source of underestimation of the effects of passive smoking. The attenuation may simply reflect the increasing weakness of a single measurement of cotinine in characterising usual passive exposure to smoking as the follow up period increases. However, in the present study population, a high initial cotinine concentration probably provides a systematic overestimate of the true longer term passive exposure to smoke, which has declined markedly in Britain during the follow up period-partly because of a declining prevalence of active smoking $^{25}$ and partly because passive exposure to smoke in public places and work places has declined. ${ }^{24}$ Long periods of follow up have been a feature of many of the earlier prospective studies, ${ }^{3}$ with most being based on follow up periods of 10 years or more; a recent report was based on a follow up period of almost 30 years. ${ }^{26}$ In studies with a single assessment of exposure, analyses based on the first decade or so of follow up will probably provide a better indication of the true relative risks than those based on prolonged follow up.

As well as providing evidence that the relative risks associated with overall passive exposure to tobacco smoke are higher than those associated with partner smoking, our results suggest that important degrees of passive exposure to smoke were widespread in the present cohort, with three quarters of non-smokers having an increased risk of CHD associated with increased exposure to cotinine. This high prevalence contrasts with the prevalences of partner smoking in studies of non-smoking men in earlier reports, which have often been well below $50 \% .^{78}$ Taken in combination with the higher estimated relative risks, the high prevalence of exposure suggests that the contribution of passive smoking to the population attributable risk of CHD could be appreciable.

\section{Passive smoking and stroke}

The earlier suggestion that passive exposure increases the risk of stroke was based on a retrospective case-control study. ${ }^{13}$ Our results do not suggest that passive exposure is related to risk of stroke, though the confidence intervals around the hazard

\section{What is already known on this topic}

Passive smoking (generally defined as living with someone who smokes) is associated with an increase in risk of coronary heart disease risk of $25-30 \%$

Passive smoking may also increase the risk of stroke, though information is limited

Living with someone who smokes is not the only relevant source of passive smoking, but few studies have taken account of all sources of exposure by relating biomarkers such as cotinine to disease outcomes

\section{What this study adds}

Higher concentrations of serum cotinine among non-smokers are associated with an excess risk of coronary heart disease of about $50-60 \%$, but show little association to risk of stroke

Risks associated with passive smoking are widespread among non-smokers in this study population

The association between serum cotinine concentration and coronary heart disease seems to decline with time since assessment of exposure, suggesting that studies examining the association of passive smoking to coronary heart disease over long follow up periods may have underestimated the true strength of association

estimates are wide and it is impossible to exclude even moderate effects of cotinine exposure on risk. However, the lack of an apparent association between passive exposure to smoking and risk of stroke suggests that the effect of passive exposure to tobacco on risk of CHD is specific and is not due to selection bias placing high risk participants in the higher cotinine groups.

\section{Conclusion}

High overall exposure to passive smoking seems to be associated with a greater excess risk of CHD than partner smoking and is widespread in non-smokers, suggesting that the effects of passive smoking may have been underestimated in earlier studies. Further prospective studies of the association between cotinine (or similar biomarkers) and risk of CHD will help to assess the effects of passive smoking on cardiovascular disease with greater precision. In the meantime, our results add to the weight of evidence suggesting that exposure to passive smoking is a public health hazard and should be minimised.

Contributors: PHW and DGC had the idea for this paper and raised a grant with MJJ and MW to carry out the study. CF and AB provided biochemical analyses; JAG and JRE provided statistical analyses. All authors contributed to the writing of the paper. PHW is guarantor.

Funding: The analysis of cotinine measurements was supported by a Project Grant from the BUPA Foundation. The British regional heart study is funded by the British Heart Foundation and the Department of Health. Competing interests: None declared.

Ethical approval: Ethical approval was provided by the Medical Research Council and subsequently by the relevant local and multicentre research ethics committees.

1 Parish S, Collins R, Peto R, Youngman L, Barton J, Jayne K, et al. Cigarette smoking, tar yields, and non-fatal myocardial infarction: 14000 cases and 32000 controls in the United Kingdom. The international studies of infarct survival (ISIS) collaborators. BMJ United Kingdom. The international studies of infarct survival (ISIS) collaborators. BMJ
1995;311:471-7.

2 Law MR, Morris JK, Wald NJ. Environmental tobacco smoke exposure and ischaemic heart disease: an evaluation of the evidence. BMJ 1997;315:973-80. 
3 He J, Vupputuri S, Allen K, Prerost MR, Hughes J, Whelton PK. Passive smoking and the risk of coronary heart disease-a meta-analysis of epidemiologic studies. $N$ Engl J Med 1999;340:920-6.

4 Hirayama T. Passive smoking. N Z Med J 1990;103:54

5 Garland C, Barrett-Connor E, Suarez L, Criqui MH, Wingard DL. Effects of passive smoking on ischemic heart disease mortality of nonsmokers. A prospective study. $\mathrm{Am} J$ Epidemiol 1985; 121:645-50.

6 Butler TL. The relation of passive smoking to various health outcomes among Seventh Day Adventists in California. Los Angeles: University of California, 1988. (PhD thesis.)

Sandler DP, Comstock GW, Helsing KJ, Shore DL. Deaths from all causes in non-smokers who lived with smokers. Am J Public Health 1989;79:163-7.

8 Hole DJ, Gillis CR, Chopra C, Hawthorne VM. Passive smoking and cardiorespiratory health in a general population in the west of Scotland. BMJ 1989;299:423-7.

9 Humble C, Croft J, Gerber A, Casper M, Hames CG, Tyroler HA. Passive smoking and 20-year cardiovascular disease mortality among nonsmoking wives, Evans County, Georgia. Am J Public Health 1990;80:599-601

10 Svendsen KH, Kuller LH, Martin MJ, Ockene JK. Effects of passive smoking in the Multiple Risk Factor Intervention Trial. Am J Epidemiol 1987;126:783-95.

11 Steenland K, Thun M, Lally C, Heath C, Jr. Environmental tobacco smoke and coronary heart disease in the American Cancer Society CPS-II cohort. Circulation 1996;94:622-8.

12 Kawachi I, Colditz GA, Speizer FE, Manson JE, Stampfer MJ, Willett WC, et al. A prospective study of passive smoking and coronary heart disease. Circulation 1997;95:2374-9.

13 Bonita R, Duncan J, Truelsen T, Jackson RT, Beaglehole R. Passive smoking as well as active smoking increases the risk of acute stroke. Tob Control 1999;8:156-60.

14 Jarvis MJ, Feyerabend C, Bryant A, Hedges B, Primatesta P. Passive smoking in the home: plasma cotinine concentrations in non-smokers with smoking partners. Tob Control 2001;10:368-74

15 Jarvis MJ, Foulds J, Feyerabend C. Exposure to passive smoking among bar staff. $\mathrm{Br}$ J Addict 1992;87:111-3.

16 Jarvis M, Tunstall-Pedoe H, Feyerabend C, Vesey C, Salloojee Y. Biochemical markers of smoke absorption and self reported exposure to passive smoking. J Epidemiol Community Health 1984;38:335-9.

17 Tunstall-Pedoe H, Brown CA, Woodward M, Tavendale R. Passive smoking by self report and serum cotinine and the prevalence of respiratory and coronary heart
disease in the Scottish heart health study.J Epidemiol Community Health 1995;49:139-43.

18 Walker M, Shaper AG, Lennon L, Whincup PH. Twenty year follow-up of a cohort Walker M, Shaper AG, Lennon L, Whincup PH. Twenty year follow-up of a cohor
based in general practices in 24 British towns. J Public Health Med 2000;22:479-85.

19 Feyerabend C, Russell MA. A rapid gas-liquid chromatographic method for the determination of cotinine and nicotine in biological fluids. J Pharm Pharmaco $1990 ; 42: 450-2$
20 Jarvis MJ, Tunstall-Pedoe H, Feyerabend C, Vesey C, Saloojee Y. Comparison of tests used to distinguish smokers from nonsmokers. Am J Public Health 1987;77:1435-8.

21 Shaper AG, Wannamethee G, Whincup P. Alcohol and blood pressure in middle-aged British men.J Hum Hypertens 1988;2:71-8.

22 Shaper AG, Wannamethee G, Weatherall R. Physical activity and ischaemic heart disease in middle-aged British men. Br Heart J 1991;66:384-94.

23 Benowitz NL. Cotinine as a biomarker of environmental tobacco smoke exposure. Epidemiol Rev 1996;18:188-204.

24 Jarvis MJ, Goddard E, Higgins V, Feyerabend C, Bryant A, Cook DG. Children's exposure to passive smoking in England since the 1980s: cotinine evidence from population surveys. BMJ 2000;321:343-5.

25 Walker A, O'Brien M, Traynor J, Fox K, Goddard E, Foster K. Living in Britain: results from the 2001 general household survey. London: Stationery Office, 2002.

26 Enstrom JE, Kabat GC. Environmental tobacco smoke and tobacco related mortality in a prospective study of Californians, 1960-98. BMJ 2003;326:1057-67.

(Accepted 6 May 2004)

doi $10.1136 /$ bmj. .38146 .427188 .55

Department of Community Health Sciences, St George's Hospital Medical School, London SW17 0RE

Peter H Whincup professor of cardiovascular epidemiology

Julie A Gilg research statistician

Derek G Cook professor of epidemiology

Department of Primary Care and Population Sciences, Royal Free Campus, Royal Free and University College Medical School, London NW3 2PF

Jonathan R Emberson BHF junior research fellow

Mary Walker research administrator

Cancer Research UK Health Behaviour Research Unit, Department of

Epidemiology and Public Health, Royal Free and University College Medical

School, London WC1E 6BT

Martin J Jarvis professor of health psychology

Medical Toxicology Unit, New Cross Hospital, London SE14 5ER

Colin Feyerabend principal biochemist

Andrew Bryant senior analyst

Correspondence to: P H Whincup p.whincup@sghms.ac.uk 